\title{
Should dental technicians play a greater role in the education of foundation dentists?
}

\author{
Philip J. Radford, ${ }^{\star 1}$ John Walton² and Ronan McManus ${ }^{3}$
}

\section{Key points}

Dental technicians play an important role in the education of foundation dentists in some dental practices.
Dental technicians can provide an additional source of feedback for foundation dentists and may encourage them to revisit concepts taught in undergraduate education.
Encouraging foundation dentists to communicate effectively and build rapport with technicians is important for the profession.

\begin{abstract}
In some dental foundation training (DFT) practices, many generations of foundation dentists (FDs) have benefited from being encouraged to build close working relationships with dental technicians. Recent work suggests that new graduates may require additional support with the technical aspects of clinical work due to reduced clinical exposure in undergraduate education. This opinion paper therefore describes how involvement of technical colleagues in the education of FDs could provide important additional feedback on their work and draws upon the concept of 'spiral learning'. It goes on to argue that these opportunities are vital in building mutual respect and the ability to communicate effectively with members of the dental team. Ingraining this approach in FDs is important for their future careers and for the dental profession.
\end{abstract}

\section{Introduction}

Discussing a prescription made to a dental technician in person can hold far greater value than the use of a written laboratory ticket alone. ${ }^{1}$ Crucially, this has the potential to translate into a higher quality of patient care. There are, however, further important benefits from cultivating close working relationships with all members of the dental team. In this paper, we will set out why encouraging foundation dentists (FDs) to meet and build rapport with their technical colleagues in person is important, and also how it can have educational benefits in this crucial phase of their careers.

\section{The DFT curriculum}

The dental foundation training (DFT) curriculum states that an FD should be able to demonstrate the ability to 'prescribe (verbally

'Dental Core Trainee, HEE Yorkshire and the Humber, UK; ${ }^{2}$ Dental Technician, Walton Ceramics, 266 Kimberworth Road, Rotherham, 561 1HG, UK; ${ }^{3}$ Educational Supervisor and Practice Principal, Kimberworth Park Dental Practice, 248

Kimberworth Park Road, Rotherham, S61 3JN, UK

*Correspondence to: Philip Radford

Email address: philip.radford2@nhs.net

Refereed Paper.

Accepted 15 July 2020

https://doi.org/10.1038/s41415-020-2337-5 and in writing) to the dental healthcare team.' This is supported by the sixth GDC Standard concerning working with colleagues in the patient's best interests, with specific reference made to the need to 'communicate clearly and effectively with other team members and colleagues in the interests of patients. ${ }^{3}$ Previous work has demonstrated that, while newly qualified dentists are thought to communicate with technicians better than their more experienced colleagues, dental schools were not preparing graduates to communicate knowledgably with their dental laboratories. ${ }^{4}$ With this in mind, and considering that the DFT programme encourages protected time for weekly tutorials, facilitating FDs to visit the laboratory to meet their technical colleagues and to enquire specifically about what written information on laboratory tickets would aid communication, is potentially of great value. Before even considering possible educational opportunities, an FD needs to know what services and materials a certain laboratory can provide and this is surely best discussed with the technician. Furthermore, entering into a dialogue with a technical colleague can lead to better understanding of some of the more challenging aspects of their role; for example, fabrication of a correctly shade-matched and characterised single-unit anterior restoration. Conversations may highlight that the technician requires a standardised photograph of the patient to produce a restoration with both the best-matched shades and appropriate surface anatomy, as has been suggested in the literature. ${ }^{5}$

\section{The power of feedback}

Experienced technicians have a wealth of experience in examining tooth preparations for extra-coronal restorations, in assessing the occlusion or in assessing available undercut in designing partial dentures. Bench-side technicians may feel most comfortable when sharing their knowledge in the familiar environment of the laboratory with numerous live cases around them. Recent evidence has demonstrated that a large proportion of surveyed DFT educational supervisors (ESs) perceive that the abilities of FDs in clinical areas such as 'crown and bridge' and 'removable prosthodontics' are unsatisfactory. ${ }^{6}$ Furthermore, it has been suggested that successful completion of an undergraduate dental degree may not provide the graduate with the skills expected from them upon entry into DFT, especially, and by their own admission, in skills that are developed through 'clinical exposure. ${ }^{7,8}$ The positive impact of formative feedback on student achievement is well documented. ${ }^{9}$ Where there are concerns within the profession about the technical abilities of 
newly qualified graduates, ensuring that they are encouraged to utilise all sources of educational feedback available to them is important. An FD who, after meeting their technician colleagues, is prepared to seek feedback and advice from them will further their understanding of what constitutes high-quality impressions and preparations, and appropriate denture designs. A technician may even be prepared to audit the impressions provided to their laboratory by the FD and provide subsequent feedback. This could encourage lifelong learning from colleagues and cultivate a culture of unity and understanding between members of the dental team which will, in turn, improve patient care. It should be noted that, at present, FDs are encouraged to invite dental technicians to give feedback as part of the 'multi-source feedback' process on the electronic portfolio system. In this process, a minimum of ten members of the dental team provide specific feedback on their interactions with the dentist and anecdotal reports suggest that technicians are not always selected to be part of this process. This exercise has the potential to be more meaningful if the FD has worked closely with their technical colleagues.

\section{Spiral learning}

'Spiral learning' is a way of organising learning whereby topics are revisited and applied to increasingly demanding scenarios during the course of training. ${ }^{10}$ FDs develop their clinical skills and knowledge through experiential learning. ${ }^{11}$ Meeting the new demands of working in NHS practice - for example, efficiently capturing a subgingival distal margin on a crown preparation in a silicone impression - inevitably leads to experiences of success and failure. In such a case, experiences of failure encourage the realisation that the use of retraction cord and a dry environment is critical. This is more valuable than being told in a lecture or placing the retraction cord on a phantom head. FDs may learn a great deal from evaluating poor-quality impressions that have been cast up. This could be undertaken if they have reattempted impressions of a crown prep multiple times and provided all available impressions to the technician. A cast poured from an impression that has detached from the tray is likely to be distorted, and being able to hold and compare such casts is a rich learning experience. ${ }^{12}$ The concept of 'spiral learning' acknowledges that initial pre-clinical experiences are important but that there is a need to revisit them at undergraduate and foundation level. Personal reflection is of the greatest importance, but visiting the laboratory to discuss study models of a live case with an enthusiastic technician colleague may well assist FDs in reawakening some of the concepts taught as part of pre-clinical studies. The concepts, now contextualised in the workplace, will have new and added relevance. Recent work in the North East of England evidences that educators acknowledge the importance of providing a 'continuum of education' between undergraduate and postgraduate dental education. ${ }^{13}$ While initial interactions may be encouraged or facilitated by the ES, as part of becoming clinicians who take responsibility for their own lifelong learning, FDs should be formally encouraged to interact with members of the dental team independently to prepare them for the future.

\section{Evaluation}

Some members of the profession may feel that ideas set out in this paper are too idealistic. In some practices and laboratories, despite numerous anecdotal reports of this type of integrated education being a successful and an important part of FD training, these arrangements may not be possible. While the authors are not aware of any formal arrangements by which technicians are involved in DFT, laboratory visits and interaction are encouraged by many training programme directors who coordinate the education of small groups of FDs and their ESs. Many DFT posts take place in well-established practices with longstanding close relationships with local dental laboratories, whose teams enjoy contributing to the education of recently qualified dentists. It can be argued that it is unrealistic to ask technicians to give up their valuable time for FDs for free and that these visits could reduce time available for patient interactions. However, it is hard to place a financial value on effective communication, the mutual respect created and the avoidance of 'remakes'. ESs may choose to allocate some of their budget for remunerating dental technicians for the educational opportunities that they provide. Dental technicians have a wealth of knowledge and experience to share, which is not often incorporated into FD teaching in the form of formal presentations on study days. They may be more willing to share their expertise on a personal level in the familiar environment of the laboratory.

\section{Conclusion}

Recent work has highlighted how DFT ESs perceive the technical abilities of recent UK dental graduates. Good communication with patients and colleagues is the cornerstone of providing high-quality dental care. FDs have the potential to gain rich educational experiences by being encouraged to cultivate a close working relationship with their technical colleagues. Dental technicians can offer a different and additional perspective on an FD's clinical work, which can form the basis of valuable feedback and facilitate revisiting of important knowledge introduced and developed at undergraduate level. A unified dental team produces highquality patient care and it can be argued that there is no better time to formally ingrain this philosophy in impressionable dentists than during their foundation training year.

\section{Acknowledgements}

The authors would like to thank Jason Atkinson, Associate Postgraduate Dean (Health Education England Yorkshire and the Humber Deanery) for his critical review of the manuscript.

\section{References}

1. Davenport J C, Basker R M, Heath J R et al. Communication between the dentist and the dental technician. Br Dent J 2000; 189: 471-474.

2. COPDEND. Dental Foundation Training Curriculum 2015. Available at https://www.copdend.org/ wp-content/uploads/2018/08/Curriculum-2016Printable-reverse-colourway.pdf (accessed June 2020).

3. General Dental Council. Standards for the Dental Team. 2019. Available online at https://www.gdc-uk. org/information-standards-guidance/standards-andguidance/standards-for-the-dental-team/ (accessed June 2020).

4. Juszczyk A S, Clark R F K, Radford D R. UK dental laboratory technicians' views on the efficacy and teaching of clinical-laboratory communication. BrDent $J$ 2009; DOI: 10.1038/sj.bdj.2009.434.

5. Stevenson B. Current methods of shade matching in dentistry: A review of the supporting literature. Dent Update 2017; 36: 270-276.

6. Oxley C J, Dennick R, Batchelor P. The standard of newly qualified dental graduates - foundation trainer perceptions. Br Dent J 2017; 222: 391-395.

7. Ali K, Tredwin C, Kay E J, Slade A, Pooler J. Preparedness of dental graduates for foundation training: a qualitative study. Br Dent J 2014; 217: 145-149.

8. Ray M, Milston A, Doherty P, Crean S. How prepared are foundation dentists in England and Wales for independen general dental practice? Br Dent J 2017; 223: 359-368.

9. Hattie J, Timperley H. The power of feedback. Rev of Educ Res 2007; 77: 81-112.

10. Harden R M, Stevenson M, Downie W W, Wilson G M Assessment of clinical competence using objective structured examination. Br Med J 1975; 1: 447-451.

11. Kolb D. Experiential learning: experience as the source of learning and development. Englewood Cliffs, NJ: Prentice-Hall, 1984.

12. Wassell R, Barker D, Walls A. Crowns and other extra-coronal restorations: Impression materials and technique. Br Dent J 2002; 192: 679-690.

13. Blaylock P, Ellis J, McCracken $G$. The transition from dental school to postgraduate dental foundation training: strengthening the interaction between stakeholders. Br Dent J 2018; 224: 269-273. 